\title{
Ordo amoris como determinante del amor y odio en Max Scheler
}

\author{
MARCELO CHAPARRO VEAS \\ Universidad Católica del Maule (Chile) \\ mchaparr@ucm.cl
}

\begin{abstract}
Resumen
El presente artículo pretende destacar que las respuestas afectivas de los seres humanos ante la realidad (personas y cosas) son constitutivas de los juicios morales desde dos perspectivas: a) un ordo amoris objetivo con funciones normativas; b) un ordo amoris descriptivo que explica las variaciones en los juicios morales. El problema filosófico consiste en que la descripción de la afectividad suele ser abordada por ciencias empíricas (historia, psicología, etnología, etc.) y es parte de la casuística. Pero, desde la perspectiva fenomenológica de Max Scheler se hace posible su abordaje filosófico, sin caer en la casuística. De modo análogo, a lo que sucede en la lógica y su tratamiento de las falacias, la axiología fenomenológica puede describir la afectividad en busca de aquellos elementos que distorsionan el juicio moral.
\end{abstract}

Palabras clave: axiología, fenomenología, ética, Max Scheler, ordo amoris.

\section{Ordo amoris as a determinant of love and hate in Max Scheler}

\begin{abstract}
This article aims to emphasize that affective responses of human beings to reality (people and things) are constitutive of moral judgments from two perspectives: a) an objective ordo amoris with normative functions; b) a descriptive ordo amoris, which explains the variety of moral judgments. The philosophical problem consists in the fact that description of affectivity is usually examined by empirical sciences (bistory, psychology, ethnology, etc.) and is part of casuistry. But from the point of view of Max Scheler's phenomenology it is possible to study this issue without the tendency to casuistry. In a similar way to logic and its dealing with fallacies, phenomenological axiology is able describe emotions seeking those elements that distort moral judgment.
\end{abstract}

Key words: axiology, phenomenology, ethics, Max Scheler, ordo amoris.

Doctor en Filosofía, Universidad Católica de Valparaíso (Chile). Profesor en la Facultad de Filosofía y Ciencias Religiosas de la Universidad Católica del Maule (Talca). Entre sus publicaciones recientes destaca "Max Scheler y el valor como materia de la ética" (2012) y "El problema del deber en la ética de los valores de Max Scheler" (2013). 


\section{Introducción}

Hace ya muchos años que Ortega (1983: 316) llamó la atención sobre la curiosa situación de los valores en su época. Destacó que un autor tan lejano a la teoría de los valores como fue Kant (1998) incorporaba la expresión «valor»-no de un modo retórico, sino dentro de la arquitectura misma de la moral- como un problema central en la fundamentación de la Ética: la ética filosófica debe establecer el valor moral de la acción (Kant, 1998: 62-63). Por otra parte, hay autores que sencillamente son contrarios a la teoría del valor, pero se cuidan mucho de afirmar que los valores no existen. Heidegger (2004: 66-67) sostiene lo siguiente:

El pensar contra "los valores" no pretende que todo lo que se declara como "valor" - esto es, la "cultura", el "arte", la "ciencia", la "dignidad humana", el "mundo" y "dios"- sea carente de valor. De lo que se trata es de admitir de una vez que al designar a algo como "valor" se está privando precisamente a lo así valorado de su importancia.

Holzapfel (2000), a su vez, siguiendo a Heidegger, comparte el juicio negativo sobre la irrupción de la teoría de los valores en la historia de la filosofía occidental. Zubiri (1993: 357), por su parte, sostiene que: «Esta historia de los valores ha sido la tortura de la filosofía desde hace setenta años». Pero, en otro lugar, en nota a pie de página se indica que no está negando la existencia de los valores (Zubiri, 1993: 214). Otros autores, como es Aranguren (2003: 70-76, 81-84), dedican capítulos enteros a criticar duramente la ética de los valores, pero en otros muchos lugares de la misma obra incluyen de modo positivo la alusión a los valores morales.

Quiero que se entienda bien lo dicho. No se está diciendo que los autores señalados más arriba sean incoherentes o que haya algún tipo de defecto en la argumentación o en la intelección de los problemas. No es que se piense que haya una mala comprensión de la obra de Scheler o de la ética fenomenológica de los valores en general. Lejos se está de tal pretensión. Sólo se quiere interpretar estas formulaciones - lejanas, contrarias y críticas - como un signo inequívoco de que la expresión «valor» es un fenómeno irreductible e inexcusable al interior del juicio moral, puesto que la expulsión completa del valor de toda forma de discusión filosófica aparece ante los mismos críticos como problemática ${ }^{1}$.

\footnotetext{
1 Probablemente el problema que hay en las críticas se refiera más bien al uso y abuso del lenguaje valórico. Lenguaje utilizado por su función retórica-afectiva y no como saber efectivo sobre las cosas. Uso que corre el riesgo de convertirse en estéril habladuría, más propio de consignas en manos de demagogos que de filósofos. Y que
} 
Parece que el valor pertenece a esa categoría de conceptos que siendo problemáticos e incómodos de ser manejados intelectualmente no pueden ser abandonados porque se refieren a orbes de problemas que solo ellos pueden nombrar. Así, con porfía inusitada dichos conceptos vuelven a aparecer una y otra vez en los lugares más inesperados de las argumentaciones. Y no de un modo accesorio, sino como parte constituyente de la arquitectura de la argumentación ética.

Lo anterior requiere algunas precisiones. Una primera distinción se refiere a la «realidad misma» del valor y su relación con los argumentos éticos con los cuales se intenta describir o bien desestimar a los valores. En el nivel de discusión teórica es posible desconocerle al «valon» su capacidad para dar cuenta del rostro «valórico» de personas y cosas; pero los argumentos no evitan la aparición de los valores en la experiencia moral. Vale decir, parece muy improbable no admitir la experiencia de que los sujetos morales atribuyan mucha importancia a otras personas y a ciertas cosas respecto de su propia realización. Como tampoco parece que se pueda eliminar de la experiencia que las distintas facetas que presentan cosas y personas no sean indiferentes. O que rara vez sucede —salvo en casos patológicos (Damasio, 1996: 73-100)-que al interactuar con el mundo circundante a las personas este le aparezca como neutro o plano desde el punto de vista afectivo. Vale decir, parece sensato admitir que las personas realizan juicios evaluativos — que no coinciden con los juicios descriptivos de la realidad- cuyo rasgo más distintivo es el compromiso afectivo de la persona con lo evaluado. Incluso desde áreas tan lejanas como la neurociencia se ha ido imponiendo la idea que la vida efectiva es de una importancia meridiana en la constitución del ser humano (Damasio, 1996; 2000; 2011). A su vez, se ha ido imponiendo la idea de una neuro-ética en la que son las emociones (las bases neuronales del cerebro ético) quienes determinan la riqueza moral de las personas, pues se constituye en un atajo emocional ante dilemas éticos (López, 2010).

Pero, que las personas se perciban como afectadas por las cosas puede ser interpretado de diversas maneras. Perfectamente, puede argumentarse que dicha afección es ilusoria, subjetiva o, lisa y llanamente, un engaño, como lo sostuvieron los estoicos. Al respecto, Nussbaum (2008) hace una distinción muy útil: un primer nivel descriptivo de los estoicos admitiría que el valor es un juicio evaluativo. Nussbaum acepta este nivel.

como fraseología que apela a positivos lugares comunes se sustrae de recibir objeción alguna. Al respecto, Gutiérrez (2009: 199-200) sostiene esta tesis en relación a la crítica de Heidegger a los valores. Y es posible pensar que la misma oposición a este lenguaje alambicado y dulzón se encuentra en Zubiri. 
Pero, en la Stoa hay un segundo nivel normativo que sostiene que dichos juicios evaluativos siempre son falsos. $\mathrm{Y}$ este argumento no es aceptado por Nussbaum (2008: 24).

Entonces, se sigue de la propuesta previa el siguiente paso: si se acepta de modo descriptivo que las emociones son juicios de valor sobre personas y cosas habrá que añadir que por ello pueden dichos juicios ser verdaderos y adecuados o falsos e inadecuados. Pero ¿qué efectos habría para la argumentación ética si dichas afecciones fuesen puestas, no ya como un ingrediente que ayuda al discernimiento del juicio moral, sino que fuese la fuente misma del juicio ético? De ser así, el problema se desplaza a otro nivel de discusión. Hacia aquello que afecta a las personas en su juicio evaluativo sobre la importancia que se le atribuye a personas y cosas respecto del florecimiento o desmedro de las personas afectadas. Pero, el valor de cosas y personas es problemático. Al poner la atención en la fuente que origina los juicios de estimación o rechazo parece no haber acuerdo en los autores. Algunos sostienen que son objetivos (Scheler, 2001; Hartmann, 2011). Mientras que otros, desde la neurobiología, sostienen que son culturales (López, 2010) y en general se acepta sin mayor discusión que los valores al ser tan variados solo pueden ser subjetivos. Por lo que hay que responder en lo que sigue a la siguiente pregunta: ¿Es el sujeto que estima quien da valor a las cosas o son los valores quienes hacen que el sujeto los estime como valiosos?

\section{Dificultades al interior de la axiología}

\subsection{Incorporación del juicio afectivo a la moral}

Admitir el valor como parte constitutiva del juicio moral no exime que se presenten, como parte de la argumentación, las dificultades que tiene el valor como modelo teórico de fundamentación ética. Pero otra cosa muy diferente es que no se considere la experiencia de valor como problema para la fundamentación ética misma. Vale decir, que al interior de los juicios morales es posible constatar como un ingrediente esencial suyo la presencia de estimaciones evaluativas del valor de la acción moral. Y que, en las emociones que realizan las evaluaciones de valor, se nos informa sobre la relevancia o importancia que tiene la realidad para el desarrollo de la persona ${ }^{2}$.

\footnotetext{
2 A consecuencias semejantes han llegado Nussbaum (2008) desde fuentes literarias, la filosofía estoica y Kant. Y Damasio (1994) a partir del análisis de casos de personas con lesiones cerebrales que afectan a la percepción afectiva.
} 
Partir de su negación por razones argumentativas no hace desaparecer el fenómeno. Prueba de ello es que este reaparece majaderamente, como se ha dicho más arriba. De hecho, una autora como Martha Nussbaum (2008) - que proviene de una tradición diferente a la fenomenología de Scheler, y según ella muy cercana a los estoicos y a Kant-, últimamente ha hecho hincapié en la necesidad de incorporar teóricamente a la justificación de los actos éticos, los actos evaluativos de la dimensión afectiva. El argumento de Nussbaum es que la afectividad nos informa sobre aspectos de la realidad inaccesibles a otras facetas de la vida humana y que son parte constitutiva de los juicios morales.

[...] podemos distinguir diversas características de las emociones de las cuales mi argumentación tratará de dar cuenta: su apremio y su calor; su inclinación a apoderarse de la personalidad e impulsarla a la acción con una fuerza arrolladora; su relación con vínculos importantes, con respecto a los cuales la persona define su vida; la sensación de pasividad ante ellas; su aparente relación de confrontación con la "racionalidad", en el sentido de un cálculo frío o de un análisis del tipo coste-beneficio; el estrecho vínculo entre ellas, pues la esperanza alterna de modo titubeante con el temor, o un solo acontecimiento transforma la esperanza en aflicción, o la aflicción, en busca de una causa, se expresa en forma de ira, a la vez que todas ellas pueden ser el vehículo de un amor subyacente (Nussbaum 2008: 44).

Y, además, si la teoría ética debe dar cuenta de la experiencia moral y dar criterios de evaluación del valor moral de la acción; entonces no puede dejar fuera de la discusión misma lo que comparece en las emociones: los valores.

Hay que insistir en que el no excluir los juicios de valor no implica evitar que puedan ser problemáticos, así sea porque los afectos no son confiables por su variabilidad o porque son subjetivos e irracionales. El argumento por el cual se reconoce que existe una dimensión dentro de la ética que escapa a cierto control racional o voluntario reconoce que el ser humano, al momento de decidir moralmente, no siempre (habría que describir con suficiente detalle en que momento efectivamente lo hace) realiza una evaluación consciente-racional de la moralidad de sus actos. Pero otra cosa es argumentar que la falta de racionalidad en las emociones implica, en y por sí misma, su exclusión como criterio evaluativo.

\subsection{Actitud pre-filosófica y experiencias morales}

Ante la pregunta de si las emociones pueden ser consideradas como criterio de fundamentación de la conducta ética hay que partir haciendo 
antes una distinción básica. La ética existe ya en la vida pre-filosófica y las personas no requieren de la reflexión filosófica para poder actuar de un modo moral. La vida pre-teorética posee modos propios de comprender sus experiencias y posee, a su vez, mecanismos que le permiten registrar las interpretaciones de dicha experiencia. Así, por ejemplo, es posible encontrar en textos religiosos y literarios descripciones muy pormenorizadas de dichas experiencias. Pero, que todavía se mueven en un plano particular y vivencial. No hay en dichos relatos una sistematización que justifique de modo absoluto la validez de las decisiones que los personajes literarios ejecutan.

Sin embargo, al mismo tiempo que atribuimos a los seres humanos la capacidad para reconocer y ejecutar actos morales, por contra parte debemos suspender el juicio sobre su real capacidad para elaborar teorías que den cuenta de modo racional o de modo científico de las conductas realizadas o por realizar. Reconocimiento experiencial y sistematización teorética no se dan en paralelo en todos los casos. El hecho de que las personas sean capaces de descubrir y comprender actos y juicios morales nos lleva a la siguiente dificultad: si bien es cierto que es altamente probable que las personas reconozcan la bondad o maldad de un acto, no obstante es también altamente probable que nos encontremos con que las mismas personas pueden llegar a no ser capaces de justificar de modo teorético la validez de dicha conducta. Por lo que a dichas personas puede llegar a parecerles que al acto en cuestión le falta un sentido último de su ejecución: es posible ver que algo es bueno o malo, pero no se sabe el por qué. Si se lleva la argumentación a sus últimas consecuencias se puede afirmar lo siguiente: ya que la validez del acto no ha sido justificada, resulta entonces que es evaluable solo como una decisión personal y subjetiva. De ello se sigue que el sujeto al considerar el juicio solo como subjetivo éste no puede ser considerado como objetivamente vinculante, ni para sí mismo ni para otros seres humanos. Es más, puede suceder que al subsumir la validez del juicio al fuero interno del sujeto éste no sea capaz de descubrir regularidades en las decisiones a pesar de las variaciones de la realidad. Y así puede evaluar el sujeto que variando la circunstancia real tenga que variar el contenido del juicio según sea el caso. De allí a relativizar todo juicio moral no hay mucha distancia.

Una posibilidad para salir de la situación anterior ha sido apelar a la experiencia moral de los otros. Aun aceptando que los juicios pueden sufrir variaciones, parece que la posibilidad de error disminuye si las personas tienen un mayor número de posibilidades para elegir. Es decir, se puede elegir lo mejor si las experiencias morales tienen mayor riqueza (numérica y cualitativamente). Se espera que el conocimiento moral pueda obtenerse a nivel experiencial de las decisiones que se realizan en per- 
sonas reales o en personajes literarios. Estas decisiones pueden enriquecer enormemente el abanico de respuestas morales de otras personas. Así, se puede argumentar que en circunstancias similares las personas se comportaran de una manera semejante a la de aquella persona que sirve de modelo de conducta. Vale decir, que según lo dicho parece plausible realizar la justificación de los actos morales tanto en la imitación personal de modelos de comportamiento vivenciados en personas-tipo (estos modelos pueden ser prudenciales o ideales, por ahora es indiferente para la argumentación), como en las concretas realizaciones que una sociedad determinada sanciona como correctas o incorrectas desde la perspectiva moral.

Ahora bien, apelar únicamente a dichos actos evaluativos desde la riqueza experiencial como justificación última de su validez moral es insuficiente. Toda experiencia puede ser suplantada por otra experiencia similar, incluso de signo contrario. Por ejemplo, es posible reconocer que matar a un ser humano es malo. Pero la misma persona puede aceptar que en situaciones de gravísimo daño moral asesinar puede ser considerado como la respuesta adecuada a la falta cometida. Vale decir, que el dolor real que afecta a una persona solo puede ser reparado con otro dolor de igual o mayor intensidad. Esto último lleva a la siguiente paradoja: que pueden convivir sin contradicción en una misma persona las experiencias de la repulsa y la aceptación del asesinato. A fin de cuentas, habría que reconocer a nivel teórico que matar puede ser bueno y malo. Que matar es malo en un gran número de casos, pero que no se puede exigir a nivel teórico una validez absoluta. Son las circunstancias descriptivas las que eran que la balanza de la justicia se incline en una u otra dirección. Pero, visto así, el valor moral de la acción misma queda en suspenso mientras no se pueda justificar su validez.

\subsection{El problema de la validez de los juicios morales}

A pesar de su pretensión de absolutez, la reflexión ética no reposa sobre sí misma o solo en la fuerza de las razones. La filosofía como reflexión teórica llega siempre después de que los seres humanos ya han decido actuar de una u otra forma. La ética como reflexión pensante recae sobre un objeto ya dado: la dimensión moral del ser humano ( $\mathrm{Zu}-$ biri, 1987: 343-440; Aranguren, 2006: 47-57). Pero que el ser humano tenga que comportarse moralmente no nos dice nada respecto de la real y efectiva norma de conducta con la cual guiar dicho comportarse. La reflexión filosófica añade a lo dado un nuevo elemento: la pretensión de que toda conducta humana —en principio- puede ser justificada en su corrección moral. 
Pero, la racionalidad de la justificación tiene límites. No es posible someter a toda persona a su dominio. Sólo son participes de la argumentación aquel que previamente ha aceptado las reglas propias de la argumentación racional. Pero aquel que no acepta someterse a una justificación con estas características no es posible de ser sometido desde la misma racionalidad. Parece que la obligatoriedad del cumplimiento de reglas será puesta en manos de otras instancias, distintas de la misma discusión racional. Como es el caso de que quien no respeta las normas será obligado a cumplirlas mediante castigo. Es lo que realizan las normas jurídicas. Pero, respecto de la moralidad de un acto no existen formalmente instancias ajenas al sujeto que le obliguen en su fuero interno a acatar los contenidos morales como vinculantes para sí mismo.

El siguiente paso ahora es verificar qué provoca el cumplimiento en el sujeto de lo moralmente vinculante. Pues si las personas no pueden ser obligadas externamente a cumplir lo moralmente exigible, habrá que buscar el móvil último en el sujeto mismo. ¿Qué es lo que mueve a la acción a los seres humanos? Se trata aquí de establecer de un modo sensato si existe en el ser humano alguna instancia que le permita juzgar moralmente; y, en segundo lugar, lo que es más complicado de justificar, si hay instancias ajenas a la persona que sean en y por sí mismas moralmente relevantes, sin ser por ello mandatos que violenten a los sujetos imperados. Estas dificultades llevan a realizar al interior de la discusión ética la siguiente exigencia: elaborar una teoría fundamentadora que respete en el ser humano su realidad particularmente compleja. Lo que lleva a preguntarse si existe en la realidad humana o fuera de ella instancias que permitan justificar de un modo absoluto y a priori la validez de las respuestas morales o debemos conformarnos con soluciones siempre parciales y circunstanciadas. Esto nos lleva a reconocer descriptivamente los siguientes problemas:

1. La justificación ética racional ha mostrado que los sujetos imperados pueden desconocer a la misma racionalidad su capacidad para corregir conductas que son consideradas como moralmente negativas. Por ejemplo, los argumentos a favor de la buena salud no son capaces de mover al fumador de tabaco a que deje de consumir aquello que lo daña.

2. El orbe de lo que puede ser mandado no abarca todo lo que es moralmente relevante. Scheler (2001: 40) prueba de un modo muy plausible que sólo puede mandarse evitar el mal. Vale decir, que la buena voluntad parece ser siempre reactiva ante la existencia: quiere el bien cuando no existe y aborrece el mal cuando 
existe. Pero parece que no es capaz por sí misma de proponer ideales de realización.

3. $\mathrm{Y}$, en tercer lugar, nos encontramos en el ser humano con una característica suya particularmente lábil y, de algún modo, incontrolable: las emociones en cuanto ellas mueven —en ocasiones de modo imperioso e irreflexivo- a la acción al margen de todo control voluntario o racional.

\subsection{Las emociones como juicios morales}

En este punto de la argumentación cabe recordar que las emociones han sido tema de discusión al interior de la ética casi desde sus inicios. Ejemplos de ello han sido: toda la teoría de Aristóteles sobre el tipo humano que es el incontinente, la consideración estoica de que las emociones son juicios falsos sobre las cosas. También se las incluyo como móviles de la acción - como es el sentimiento de respeto a la ley en Kantpues la razón pura no es capaz de mover a la acción. Y hay aquellos que consideran que hay emociones privilegiadas que dirigen la vida afectivamoral de las personas y grupos: Ejemplos de ello son la teoría de la empatía como sentimiento fundamental en la ética de Smith. Y el amor como emoción que descubre la jerarquía de los valores en la ética axiológica elaborada en el siglo XX por Husserl, Scheler, Hartmann y Hildebrand.

A modo de comparación con las otras instancias (razón y voluntad): se ve que la razón discursiva puede ser capaz de ocultar sus intenciones tras una cortina de argumentos, cuya veracidad no siempre es posible descubrir. Incluso para el mismo sujeto. Fíjese la atención sobre la enorme dificultad al momento de argumentar respecto de las razones por las cuales se ama a determinada persona. Es más, parece que el hecho de argumentar a favor del amor es ya una manera de distorsionar la originalidad de la emoción.

En segundo lugar, respecto de la voluntad, quien es mandado - sea interna o externamente- respecto del mandato que se obedece, en su fuero interno se auto-percibe como siendo irresponsable respecto del contenido que se obedece. La bondad se evalúa en el cumplimiento, no en lo cumplido. Ejemplo de ello es el caso de instituciones jerarquizadas donde el mandado no es responsable de sus actos, sino aquel que ha dado la orden. Entonces, si las órdenes son objetivas — vale decir, que el sujeto no las ha creado sino que las descubre- la responsabilidad al momento de cumplirlas puede reducirse a la mera formalidad del cumplimiento, sin importar el contenido mandado. Esta ha sido la argumen- 
tación de la defensa que hace Eichmann de su propia conducta: era un funcionario del Estado que solo cumplió con su deber. Ante sí mismo se consideraba inocente (Arendt, 2003).

Por otra parte, apelar a la voluntad y su buena intención no exime a la persona de las consecuencias negativas o positivas respecto de los resultados de su acción. Ejemplo de ello es el error cometido sin intención que mata a un inocente. El dolor ante la falta no dolosa cometida muestra que la buena intención no es capaz de llenar completamente la justificación del acto ante la persona y los deudores. Es más, dolor y arrepentimiento parecen ser las respuestas esperadas y no la justificación mediante la buena voluntad del fuero interno.

Lo interesante en las emociones es que si se consideran los contenidos de las respuestas afectivas del ser humano se encontrará que ellas son percibidas - por el sujeto y por aquellos que conocen dichas respuestas, como pueden ser los lectores de literatura- como posibles donantes de relevancia y sentido a lo que el sujeto realiza.

Ahora cabe preguntarse: suponiendo que las emociones nos informan - mediante evaluaciones de valor- la importancia de personas y cosas para el florecimiento personal ¿̇e supondrá, entonces, que dichos juicios de valor pueden ser a su vez evaluados - respecto de si son o no confiables- de igual modo que son evaluables los juicios lógicos o el cumplimiento del deber? Porque atribuir un gran valor a un objeto que no posee dicho valor sería considerado un juicio falso y su contrario habría que considerarlo como el verdadero. Si la cosa posee un valor ínsito, entonces, no se puede atribuir el valor positivo y negativo a la misma cosa bajo la misma circunstancia. Una de ellas necesariamente tiene que ser falsa.

Si se considerará que las emociones son juicios. Corresponde ahora hacer una aclaración conceptual: Son juicios porque en ellos se evalúa algo y dicha evaluación puede ser correcta o incorrecta. Pero son distintos de los juicios sobre la realidad o los de estados físicos de cosas. Así que deberá argumentarse en favor de su validez como juicios sobre la praxis. Esta es una novedad descubierta por la fenomenología. Pero la novedad no recae en las emociones, sino en que las emociones son tan cognoscitivas como lo puede ser la percepción visual ${ }^{3}$.

3 Ya lo hemos dicho antes, las emociones han sido parte de la ética, al menos, desde Aristóteles (las virtudes éticas recaen sobre aquella parte irracional del alma que está abierta a escuchar a la razón). Encontramos los afectos en los estoicos como una dificultad para el logro de la vida plena. San Agustín en De Civitate Dei ya se plantea la idea de un ordo amoris como la definición de lo que es la virtud. Pascal en la obra Penseés reconoce la existencia de una lógica del corazón distinta de la lógica de la razón. Smith en 
Sin embargo, parece que ha sido un cierto tipo de racionalismo kantiano el que ha puesto en tela de juicio la confianza en los sentimientos. También a las emociones, por su carácter veleidoso, se le ha expulsado de la discusión moral. Pero no podemos validar su marginación de la evaluación del juicio moral aduciendo que en la medida que un elemento se presenta como insometible a nuestros designios se puede proceder a su exclusión. Lo más sensato parece ser lo contrario, si el sistema a evaluar es complejo - como parece ser la vida moral del ser humano- la teoría debe tener tal amplitud que sea capaz de incorporar también aquellos elementos que se resisten a los designios del modelo teórico de turno.

En lo que sigue, como una manera de responder a las aporías arriba presentadas se pretende mostrar que la fenomenología de Scheler ha podido presentar de un modo sensato un proyecto de fundamentación ética que es capaz de hacer comprensible, por un lado, las exigencias normativas de validez a priori de los juicios morales y, por otro lado, sin desconocer lo polifacético del mundo afectivo del ser humano, es capaz de dar cuenta de aquellos elementos descriptivos que hacen posible el error moral según las variaciones individuales, históricas y sociales. Entonces, hay que mostrar que tanto lo normativo al interior de la ética como los aspectos descriptivos de las decisiones morales son abordables filosóficamente y se pueden articular dentro de lo que se denomina niveles del ordo amoris 4 .

\section{Niveles del ordo amoris}

Tras lo expuesto pasaremos a considerar los réditos filosóficos de una posición filosófica que atribuye a la conciencia afectiva y a su correlato objetivo - vale decir el valor - la condición de fundamentación de la ética (Scheler, 2001; Hartmann, 2011). Esto quiere decir que la ética de los valores propone que en la afectividad humana radicaría la posibilidad de justificar de un modo absoluto y a priori los juicios morales. Así se

The Theory of Moral Sentiments ve que el origen de la moral radica en cierto tipo de sentimientos: la simpatía.

4 Los aspectos descriptivos que indicamos más arriba pueden ser abordables por disciplinas científicas: etnología, sociología, historia, etc. Sin embargo, es posible argumentar que esos elementos históricos y sociales pueden ser abordados filosóficamente en un cierto tipo de teoría comprensiva de las variaciones en el ethos. Teoría que haría comprensible en el tiempo el enriquecimiento del conocimiento moral y, por otro lado, permitiría, analógicamente, elaborar una teoría de las falacias morales (individuales, sociales históricas). 
intentará mostrar como la axiología, en cuanto teoría ética, se hace cargo de hacer comprensible que la conciencia moral es una conciencia estimativa, según la expresión de Ortega (1983) que responde al llamado que le hacen los valores (Hildebrand, 1983).

La discusión se puede iniciar con el problema que propone Max Scheler (2008: 21):

Me encuentro en un inmenso mundo de objetos sensibles y espirituales que conmueven incesantemente mi corazón y mis pasiones. Sé que tanto los objetos que llego a conocer por la percepción y el pensamiento, como aquellos que quiero, elijo, produzco, con que trato, dependen del juego de este movimiento de mi corazón. De aquí se deduce para mí que toda especie de autenticidad o falsedad y error de mi vida y de mis tendencias, depende de que exista un orden justo y objetivo en estas incitaciones de mi amor y de mi odio, de mi inclinación y de mi aversión, de mis múltiples intereses por las cosas de este mundo, y de que sea posible imprimir a mi ánimo este ordo amoris.

El problema ético consiste ahora en averiguar si los juicios de valor son verdaderos o falsos. El modo de evaluar su validez pasará por verificar si a los emociones (el amor y el odio en concreto) les corresponde «un orden justo y objetivo». Orden al cual tendría que adecuarse, para ser verdadero, el ánimo de la persona. Entonces, el problema ético se reduce, a partir de este momento, a establecer qué es y cómo funciona respecto de las personas el ordo amoris.

$\mathrm{Al}$ investigar la esencia de un individuo, una época histórica, una familia, un pueblo, una nación u otras unidades sociales cualesquiera, habré llegado a conocerla y comprenderla en su realidad más profunda si he conocido el sistema, articulado en cierta forma, de sus efectivas estimaciones y preferencias. Llamo a este sistema el ethos de este sujeto (...). La concepción del mundo, así como las acciones y hechos del sujeto van regidas desde un principio por este sistema (Scheler, 2008: 70).

Este ordo amoris es presentado como el núcleo de la vida moral de personas y pueblos. Pero ¿cómo se articulan las variadas preferencias humanas con un orden objetivo de valores? La propuesta es: distinguiendo tres niveles fenomenológicamente separables: 1. El ordo amoris objetivo, 2. El ordo amoris normativo que, en cuanto conocido, se le propone a la voluntad y la inteligencia, 3. El ordo amoris descriptivo en cuanto efectivamente realizado por sujetos y pueblos.

A continuación se describirán en qué consisten cada uno de ellos. 


\subsection{Ordo amoris objetivo}

$\mathrm{Al}$ interior de lo dado a la percepción afectiva se puede describir el saber objeto de las emociones, vale decir, la totalidad de contenidos que percibe la afectividad. Eso obliga a realizar una distinción al interior mismo del conocimiento objetivo. Ya se ha dicho que existe un saber ético pre-filosófico que evalúa la moralidad de las actitudes y de los actos. Pero, ¿desde dónde se evalúa? ¿Algún parámetro tiene que estar dado a las personas en su experiencia para hacer la comparación entre los actos y aquello que los valida? Por ejemplo, las personas pueden determinar lo que es la verdadera amistad si se la separa del encuentro humano por interés.

Aquí comparece ante las personas un dato fenomenológico. Siguiendo con el ejemplo anterior: La verdadera amistad posee rasgos esenciales que deben estar presentes en la evaluación que se hace de los amigos. Si se atiende a lo dicho, aquí nos enfrentamos a un tipo de objetividad distinta de la propia de los objetos físicos que se hacen presente a la percepción y a la investigación intelectual. Como consecuencia de lo dicho, Scheler se ve obligado a describir una variante dentro de la objetividad: junto a los objetos corpóreos es posible experimentar objetos ideales. Existen (poco importa en este momento el modo de entender esta existencia) o al menos poseen independencia respecto del sujeto que valora, unas entidades cuyo contenido es moral. Así el conocimiento moral objetivo sería aquel saber (pre-filosófico y filosófico) acerca de esos objetos. Los fenomenólogos que han abordado el tema coinciden en circunscribir el orbe de objetos con contenido moral a los valores (Husserl, Scheler, Hartmann, Hildebrand). Y, el dato objetivo es que los valores están organizados en una jerarquía. Esto determina que el objeto de investigación de la ética consiste en descubrir y describir este orden jerárquico. Los valores se presentan con tal riqueza de matices que ninguna época o persona es capaz de agotar todo su contenido. La historia muestra cómo los seres humanos han ido descubriendo nuevos valores que completan, pero no agotan el saber de lo valioso. Este orden jerárquico corresponde al ordo amoris objetivo. El que, semejante a la riqueza de la realidad, no se agota en lo que los seres humanos comprenden sobre dicho conjunto organizado de valores. Un autor contemporáneo a Scheler expresó este problema en los siguientes términos:

Una vez que se ha comprendido que esos mismos valores, los únicos que pueden guiar nuestro querer y nuestro hacer, nos salen al encuentro en mil ocasiones, realizados en personas y situaciones, en relaciones y acontecimientos; que nos envuelven a cada hora, nos conducen y —mucho más allá 
de nuestra limitada capacidad de comprensión - llenan de luz y brillo nuestra existencia, se está ante [...] la pregunta ética básica: ¿A qué se dirige el tener abierto los ojos para tomar parte en ello? ¿Qué es lo valioso en la vi$\mathrm{da}$, en el mundo en general? Para ser hombre en el pleno sentido de la palabra, ¿de qué hay que apropiarse? ¿Qué hay que entender, apreciar? ¿De qué nos falta aún el sentido, el órgano, de modo que lo tenemos que configurar, aguzar y educar en nosotros? (Hartmann, 2011: 52-53).

Si nos fijamos el orden objetivo posee una dinámica que nos está incitando a tomar partido respecto de ese mundo de valoraciones. Lo cual nos lleva a preguntarnos por el segundo nivel del ordo amoris: su carácter normativo.

\subsection{Ordo amoris normativo}

$\mathrm{Al}$ interior del saber objeto podemos encontrar que ciertos contenidos son aceptados y otros rechazados. ¿Qué justifica esta selección de lo aceptable y la rechazable? La propuesta de la fenomenología de Scheler es que hay un saber afectivo acerca de los valores, en tanto en cuanto son ofrecidos a la voluntad para su realización. $\mathrm{O}$, dicho de otro modo, es la jerarquía objetiva de los valores en cuanto conocida y ofrecida a la voluntad en los actos de preferir y postergar (Scheler, 2008: 23). Y, esto es lo que usualmente se ha entendido como el tema de elucidación de la ética filosófica.

De aquí se ha seguido para la Ética la consecuencia siguiente: que, a lo largo de su historia, se constituyó bien como Ética absoluta y apriórica y, por esto, racional, o bien como una Ética relativa, empírica y emocional. Apenas se ha sido planteado el problema de si no debiera y podría darse una Ética absoluta apriórica y emocional (Scheler, 2001: 357).

Pero la argumentación respecto de la ética que pretende una validez absoluta y a priori cree haber encontrado el suelo firme para su pretensión en la racionalidad del ser humano; sin embargo, aquí se propone como problema, una ética empírica y afectiva que se hace cargo de las variaciones históricas del saber moral. ¿Con esto se pierde la validez absoluta y a priori de las normas morales? Hay argumentos que muestran cierta ventaja en la filosofía de Scheler en que es posible sostener, aunque en niveles distintos, la validez de un saber a priori y absoluto para la moral. Saber que es compatible con las variaciones históricas y personales de la moral. Esto es lo que parece ser el proyecto filosófico que para la moral ha pensado Scheler. 
La pretensión de dar a la ética una urdiembre afectiva obliga a Scheler a descubrir en las estimaciones su estructura interna. Dicha estructura debería poseer una legalidad análoga a la de la lógica para validar las estimaciones mismas. Algo así como una lógica formal que permitiera validar los juicios del amor y odio, del preferir y postergar, respecto de su concordancia o discordancia con una escala de valores cuya validez ya ha sido establecida. Pero, en su carácter análogo, Scheler sigue la intuición de Pascal según la cual el corazón posee razones que la misma racionalidad no conoce, es el ordo amoris en su dimensión normativa. «El corazón posee algo estrictamente análogo a la lógica, en su propio dominio, que, sin embargo, no coincide con la lógica del entendimiento» (Scheler, 2008: 55).

No obstante lo anterior, Scheler es consciente de que las variaciones históricas y sociales en las preferencias y en la dirección del amor y del odio representan un problema filosófico en sí mismo. Y que debe ser abordado con las herramientas de la fenomenología.

El odio es, por consiguiente, siempre y en todas partes, una rebelión de nuestro corazón y de nuestro espíritu contra la vulneración del ordo amoris, lo mismo tratándose de una débil excitación al odio en nuestro corazón individual que tratándose de violentas revoluciones de odio como fenómeno de masa, extendido sobre la tierra y dirigido contra las capas directoras (Scheler, 2008: 22).

Es destacable que Scheler se percató que las variantes en la percepción del ordo amoris objetivo y normativo no implicaban la ruptura de su validez y su carácter a priori, sino que obligaban a la ética a abordar con sumo cuidado las variaciones, para no caer en un fácil relativismo. Lo que se propone es incorporar lo descriptivo como parte de la fundamentación misma de la moral. Es el paso hacia el ordo amoris descriptivo.

\subsection{Ordo amoris descriptivo}

Se puede pensar que respecto del saber objeto existen variaciones circunstanciadas cuyo contenido sólo puede llegar a ser conocido por la investigación de campo: etnólogos, sociólogos, historiadores, etc. Dichas variaciones sociales e históricas son, en principio, como saber objetivo, neutras desde una perspectiva moral. El científico que da cuenta de los contenidos en una cultura y tiempo determinado no puede, por prohibición de su propio método, evaluar la corrección ética o su ausencia en comparación con un modelo normativo de moralidad. 
Pero Scheler propone que la descripción de los diversos tipos humanos (históricos, individuales y sociales) y la correspondiente escala de estimaciones o de valores que trae aparejada también son susceptibles de investigación ética. También la filosofía puede evaluar la historia y la sociología de la ética desde criterios filosóficos. Sin dejar de ser por ello una descripción. Y, sin caer en una mera casuística. Que por lo demás es imposible de realizar en sí misma por la envergadura de sus infinitos casos y variantes.

Pero también es fundamental descriptivamente el concepto de ordo amoris. Porque es el medio de hallar tras los embrollados hechos de las acciones humanas moralmente relevantes, de los fenómenos de expresión, de las voliciones, costumbres, usos y obras espirituales, la sencilla estructura de los fines más elementales que se propone, al actuar, el núcleo de una persona, la fórmula moral fundamental según la cual existe y vive moralmente este sujeto (Scheler, 2008: 23).

¿Qué ventaja posee este enfoque? Los tres niveles de descripción del ordo amoris que se han propuesto justifican una cierta ventaja del enfoque fenomenológico frente a otras perspectivas ya consagradas. Los grandes modelos éticos se han organizado en torno a dos ejes fundamentalmente: establecer un fin o bien que sea capaz de dirigir en un determinado sentido toda la vida y sus realizaciones. Y, por otro lado, un principio de obligatoriedad que haga posible la realización de ciertas conductas que se consideran deseables y la postergación o castigo de aquellas otras que se consideran indeseables. Lo dramático de estos dos modelos es que, bajo ciertos aspectos muy precisos, son incompatibles. La crítica de Kant a las éticas de bienes y fines ha sido tan demoledora que incluso dentro de sus defensores ha quedado clara la conciencia que es muy difícil, si no imposible, postular la validez de éticas de contenidos, así sean estos fines sublimes o mínimos.

Por otro lado, el formalismo logra un resultado óptimo respecto de eliminar el relativismo de las acciones al proponer como criterio de moralidad la universalidad de la decisión. El problema radica en que el criterio de universalidad no permite desde sí mismo descubrir si los contenidos son moralmente relevantes en y por sí mismos.

El problema ético, entonces, radica en que las éticas de bienes proponen contenidos que no pueden ser validados universalmente. Y, por contra parte, las éticas de deberes nos proponen métodos para obtener órdenes absolutas, cuya validez no proviene del contenido sino de procesos formales. Esta dicotomía entre forma y contenido al interior de la ética parece no resolver el problema de la vida moral misma. Por lo que 
parece urgente responder positivamente a la pregunta: ¿Es posible todavía proponer una ética de contenidos que al mismo tiempo valga universalmente y sea a priori?

En gran medida responder a esta pregunta pasa por conocer la riqueza de contenidos morales que en la historia se han hecho conocidos y vigentes. A su vez, Scheler considera que la idea de un ordo amoris al interior de la fundamentación filosófica resulta ser la vía de solución al problema de la incompatibilidad entre forma y contenido en la ética anterior a la fenomenología. Veamos algunos puntos claves de esta solución:

1. Nivel de conocimiento objetivo. Desde los estoicos - Scheler se apropia de esta idea y la incorpora a su ética- se ha hecho patente que los seres humanos reaccionan ante los contenidos de la realidad con su afectividad. Dicha reacción es en relación de aquello que aparece como importante para la persona. Vale decir, existe la experiencia humana de que la realidad puede ser enjuiciada por los sentimientos o emociones. Emociones que no genera el sujeto a voluntad, sino que son reacciones frente a la provocación que suscitan las personas y las cosas. Reacciones que, a su vez, son evaluaciones respecto de la mayor o menor importancia que se debe atribuir a las objetividades para la plenitud de la persona misma o de los otros.

2. Criterio normativo para la acción. Si se considera como dato la experiencia de aquel que enjuicia la realidad según el grado de importancia asignado para la persona; entonces, desde una perspectiva filosófica, hay que establecer qué es lo que de modo objetivo (material, universal y a priori) justifica que la valoración de la importancia me permita enjuiciar la realidad. La realidad es vista desde esa nueva perspectiva que me proponen los valores: la dimensión de la importancia que se descubre en personas y cosas. La información que me dan las emociones permite enjuiciar la realidad en su importancia. $\mathrm{Y}$ en cuanto juicio puede ser verdadero o falso, adecuado o inadecuado, etc. Lo que permite establecer a priori las preferencias adecuadas a los valores según su jerarquía.

3. Criterio descriptivo para la acción. Un tercer nivel se refiere a que de hecho es posible darle importancia a aquello que no lo tiene. Eso implica, filosóficamente, realizar dos tareas: la descripción —análoga a los errores lógicos- de las falacias en los juicios morales. Que consiste en descubrir y describir las formas bajo las 
cuales es posible errar éticamente. Ejemplos de ello es la ceguera moral (Hildebrand, 1983: 53-54), el resentimiento (Scheler, 1998), los diversos tipos de ilusión (Scheler, 2001: 370). La segunda tarea consiste en estudiar los cambios en el ethos en fuentes no históricas como pueden ser las grandes obras literarias. Pues allí se describe la riqueza afectiva de un ethos epocal. Así podemos evaluar el ordo amoris de otras épocas y sociedades, porque el buen escritor puede ofrecernos esa estructura cristalina en su ejecución vital. Cito dos fragmentos de Cordua referidos a la manera que tenía Dostoiewski de presentar los personajes de sus obras que ilustran la perspectiva de descubrimiento del ordo amoris descriptivo:

El escritor pensaba, en efecto, que no era suficiente comprender una idea sino que había que darla a sentir mediante una existencia singular, representativa de la idea, cuya presencia concreta o imagen comunicara la verdad de la idea. Por eso, evitando los discursos y los formulismos, nos presenta las ideas a través de la manera cómo ellas configuran a las personas que las viven (Cordua, 2010: 328).

Y más adelante, evalúa precisamente las falencias que posee el interpretar la realidad moral sin incorporar el ordo amoris:

El escritor [...] criticó a menudo al intelectualismo abstracto de políticos y revolucionarios que aíslan al pensamiento de las emociones, las creencias, las experiencias históricas de los pueblos. La inteligencia separada del resto de la vida psíquica y social es una de las enfermedades modernas que caracterizan a los numerosos maniáticos y enfermos mentales de las novelas de Dostoievsky (Cordua, 2010: 333).

Dicho de otro modo, a la disciplina ética no solo le corresponde establecer los modos correctos, idóneos y obligatorios de conducta moral. Esa es la tarea propia de la ética en su función normativa: establecer los fundamentos de la moral. Con lo cual la filosofía puede convertirse en letra muerta apabullada por una realidad que no la escucha. Pero también, como un médico que sabe lo que es la salud, la filosofía debe ser capaz de diagnosticar las enfermedades del $e^{t h o s^{5}}$. Y, de ser posible, indi-

\footnotetext{
5 Ejemplo de esto último pueden ser considerados los textos de Scheler sobre el resentimiento, el odio al pueblo alemán, el sentido del sufrimiento, etc. Así como toda la tercera parte: Ascensos del amor de la obra Paisajes del pensamiento, de Nussbaum (2008).
} 
car un tratamiento para su cura. Esa puede ser la tarea propia de una ética filosófica descriptiva.

\section{A modo de conclusión}

La idea de un ordo amoris descriptivo no está exenta de problemas. Es posible pensar que la dimensión descriptiva es de algún modo neutra desde el punto de vista moral. Es extra-filosófica, más bien propia de ciencias empíricas. Pero, la fenomenología es por esencia descriptiva. Así que, a modo de hipótesis todavía por justificar, se puede plantear como posibilidad que la historia de la ética no sólo se debe referir a lo que la disciplina filosófica ha sido a lo largo de la historia (Camps, 2008) que a fin de cuentas revisa la historia de la ética en cuanto normativa. Pero, al menos, desde las investigaciones realizadas por Scheler ${ }^{6}$ es posible elaborar una historia descriptiva de la ética que no sólo sea un repertorio de casos, sino la descripción de aquellos tipos ideales en sus dos vertientes: tipos de errores y tipos de progresos que la ética ha realizado. Eso significa, metodológicamente, evitar una especie de solipsismo filosófico. Vale decir, que no solo en los textos de los filósofos profesionales es posible encontrar argumentos que justifiquen las conductas éticamente relevantes, sino también en otras fuentes que deberán ser consideradas como experiencias documentadas y legítimas. Dicho así, la historia y las experiencias epocales no solo pueden enriquecer la gama de respuestas éticas, sino también la fenomenología de tipos humanos. Otra consecuencia de un enfoque descriptivo en la ética es aquella que permite enriquecer las perspectivas para establecer - desde un horizonte de experiencias más amplio que el de los textos filosóficos - la validez de formulaciones que pretendiendo ser universales pueden ser solo la generalización del ethos de una época y lugar históricamente determinados.

La descripción fenomenológica que ha hecho Scheler ha revisado algunos de esos tipos humanos que han encarnado la escala de valores epocal vigente. Al revisar los autores coetáneos suyos con los que dialogó fácilmente se constata la presencia de fuentes no-filosóficas. Claros ejemplos de esto último son la utilización de ideas provenientes de $E$ l burgués de Sombart (2006), y La ética protestante y el espíritu del capitalismo de Weber (2012). El contenido de un proyecto tal debería incorporar los distintos tipos humanos que circunstancial y culturalmente han encarnado el ethos descriptivo u ordo amoris descriptivo como modelos paradigmá-

Algo semejante ha realizado en varias de sus obras Nussbaum (1992; 2008). Lo mismo puede ser dicho respecto de Bloom (1996). 
ticos. Ejemplos históricos de estos tipos han sido: el señor feudal, el burgués, el gentilhombre, el hidalgo, el dandy, el bodysatva, etc. Vale decir, que en una historia como esta se podría visualizar el desarrollo histórico (vivo y operante) de la ética en cuanto entrañada, vuelta ya hábito y que de hecho inspira la conducta efectiva de la persona.

La idea final es que no es sensato evaluar los juicios morales sin incorporar - para realizar una justa ponderación del juicio moral-aquellos elementos irracionales que, como ingredientes esenciales del juicio moral, dotan de contenido, relieve y riqueza material a la discusión ética. Vale decir la incorporación a la discusión filosófica del ordo amoris descriptivo nos permitirá reconocer y retener lo mejor de un amplio abanico de figuras humanas ideales. Ideales que permitirán pensar en una nueva figuratipo que sea capaz de descubrir aquellos valores más a los que epocalmente nos corresponde realizar como vocación y destino.

\section{REFERENCIAS}

-Aranguren, J. L. L. (2006). Ética. Madrid: Alianza Universidad Textos.

-Arendt, H. (2003). Eichmann en Jerusalén. Barcelona: Lumen.

-Bloom, A. (1996). Amor y amistad. Santiago: Andrés Bello.

-Camps, V. (comp.) (2008). Historia de la ética. Tres tomos. Barcelona: Crítica.

-Cordua, C. (2010). «Volver a leer a Dostoiewski». Revista Estudios Públicos. Santiago, $\mathrm{N}^{\circ} 117$, verano 2010, pp. 323-335.

-Crespo, M. (2012). El valor ético de la afectividad. Santiago: Ediciones Universidad Católica de Chile.

-Damasio, A. (1996). El error de Descartes. La razón de las emociones. Santiago: Andrés Bello.

-Damasio, A. (2000) Sentir lo que sucede. Cuerpo y emoción en la fábrica de la consciencia. Santiago: Andrés Bello.

-Damasio, A. (2011) En busca de Spinoza. Neurobiología de la emoción y de los sentimientos. Barcelona: Ediciones Destino.

-Gutiérrez, C. (2009). La crítica del concepto de valor en la filosofía de Heidegger. Bogotá: Ediciones Uniandes.

-Husserl, E. (1969). La filosofía como ciencia estricta. Buenos Aires: Nova.

-Hartmann, N. (2011). Ética. Madrid: Encuentro.

-Hildebrand, D. v. (1983). Ética. Madrid: Encuentro.

-Heidegger, M. (2004). Carta sobre el humanismo, Madrid: Alianza.

-Holzapfel, C. (2000). Aventura ética: Hacia una ética originaria, Santiago: LOM.

-Kant, I. (1998). Fundamentación de la metafísica de las costumbres. Madrid: EspasaCalpe.

-Kant, I. (2011). Grundlegung zur Metaphysik der Sitten. Stuttgart: Reclam.

-López, N. (2010). La búsqueda en el cerebro de la dotación ética innata y universal. Acta Pbilosophica: Rivista Internazionale de filosofia, 19 (2), 297-310.

-Nussbaum, M. (2008). Paisajes del pensamiento, Barcelona: Paidos. 
-Ortega y Gasset, J. (1983). Introducción a una estimativa. En Obras (T. VI). Madrid: Alianza Editorial.

-Scheler, M. (1954). Der Formalismus in der Ethik und die materiale Wertethik. En Gesammmelte Werke (Band 2). Bern: A. Franke AG Verlag.

-Scheler, M. (1955). Das Ressentiment im Aufbau der Moralen. En Vom Umsturz der Werte, Gesammmelte Werke (Band 3). Bern: A. Franke AG Verlag.

-Scheler, M. (1957). Ordo amoris. En Schriften aus dem Nachlaß, Band I, Zur Ethike und Erkenntnislehre, Gesammmelte Werke (Band 10). Bern: A. Franke AG Verlag.

-Scheler, M. (1998). El resentimiento en la moral. Madrid: Caparrós Editores.

-Scheler, M. (2001). Ética. Madrid: Caparrós Editores.

-Scheler, M. (2008). Ordo amoris. Madrid: Caparrós Editores.

-Sombart, W. (2006). El burgués: contribución a la historia espiritual del hombre económico moderno. Madrid: Alianza Editorial.

-Weber, M. (2012). La ética protestante y el espíritu del capitalismo. Madrid: Alianza Editorial.

-Zubiri, X. (1986). Sobre el hombre. Madrid: Alianza Editorial.

-Zubiri, X. (1993). Sobre el sentimiento y la volición. Madrid: Alianza Editorial.

Sumario: Introducción; 1. Dificultades al interior de la axiología; 1.1. Incorporación del juicio afectivo a la moral; 1.2. Actitud pre-filosófica y experiencias morales; 1.3. El problema de la validez de los juicios morales; 1.4. Las emociones como juicios morales; 2. Ordo amoris; 2.1. Ordo amoris objetivo; 2.2. Ordo amoris normativo; 2.3. Ordo amoris descriptivo; A modo de conclusión; Referencias. 